\title{
El origen divino de la subjetividad en la reflexión teológica de Juan Alfaro. \\ Las repercusiones en el hombre y las tensiones intelectuales del autor presentes en este proceso
}

\author{
Carlos Ábrigo Otey \\ UNIVERSIDAD CATÓLICA SILVA HENRÍQUEZ \\ cabrigo@ucsh.cl
}

Resumen: Este artículo es un ensamblaje de partes extraídas de mi tesis doctoral titulada "Conciencia y libertad. Una fundamentación de la condición de sujeto de la persona humana, como eje articulador transversal en la antropología teológica de Juan Alfaro”, presentada a la Facultad de Teología de la Pontificia Universidad Católica de Chile.

En esta publicación pretendo esbozar el proceso y las tensiones intelectuales que tuvo este importante teólogo español del siglo pasado para llegar a la convicción que la conciencia y la libertad, entendidas como las dimensiones que configuran la subjetividad humana, constituyen un plus divino en el proceso evolutivo del devenir cósmico.

Palabras clave: Conciencia, Libertad, Gracia, Persona, Evolución cósmica, Evolución histórica, Responsabilidad, Natural-Sobrenatural, Divinización humana.

Abstract: This article is an assembly of texts that were taken from my doctoral thesis which is titled "Conscience and liberty. A fundamentation of the condition of subject of the human person, as transversal articulator axis in the theological antrophology of Juan Alfaro". It was submited to the Theological Faculty of the Catholic Pontifical University in Chile.

I intend to outline the process and intelectual tensions that went through this important spanish theologian, in order to reach the conviction that conscience and liberty, stood as dimensions that configure human subjectivity, both establish a divine plus in the evolutionary process.

Keywords: Consciousness, Freedom, Grace, Person, Cosmic evolution, Historical evolution, Responsibility, Natural Supernatural, Human Divinization. 


\section{INTRODUCCIÓN}

El origen divino de la subjetividad ${ }^{1}$ tiene su base en el hecho de que Alfaro, en su enfoque antropológico, considera a Dios como el fundamento de la subjetividad humana.

En términos teóricos, esto quiere decir que en la reflexión del autor el aparecimiento en el mundo de la conciencia y de la libertad a través del hombre, como expresiones de la subjetividad, constituye no solo un salto cualitativo en el proceso evolutivo de la naturaleza, sino fundamentalmente la irrupción de Dios como don en ese proceso, el cual, a partir de ahí, queda orientado hacia la plenitud, sin poder alcanzarla por sus propios medios.

Es necesario señalar, sin embargo, que la convicción relativa a que Dios constituye el supuesto fundamental de la subjetividad humana, nuestro autor la va alcanzando de manera paulatina, lo cual comportará efectos interesantes, dignos de considerar:

Indudablemente, en Alfaro, la subjetividad entendida como eje articulador de su discurso ha estado presente desde el inicio de su reflexión -inserta por cierto, en esta etapa inicial, en el modelo escolástico- y se acentuará en el transcurso de los años, alentado principalmente por el

Me parece oportuno indicar aquí que la categoría subjetividad, si bien es cierto es usada en escasas ocasiones por Alfaro, ella es perfectamente identificable en su discurso post-Vaticano II, con la conciencia y la libertad. Efectivamente, expresado en términos muy sintéticos, la conciencia y la libertad, en su conjunto, vienen a constituir -en el planteamiento del autor- aquella dimensión espiritual fundante del ser personal del hombre, que lo capacita para establecer una relación con Dios en ese nivel de personas, como relación de sujetos.

En su relación con el mundo, además, esta dimensión permite al hombre descubrirse como realidad distinta a él (de cara al mundo), llamado a realizar, en esa relación, una acción transformativa creadora de cultura e historia, mediante la cual va creciendo en su desarrollo personal orientado permanentemente hacia un futuro esperanzador, que involucra también al mundo.

Esta dimensión, finalmente, capacita al hombre, en su relación a los otros, para descubrir en cada uno de ellos un valor absoluto, inherente a un yo personal, en virtud de lo cual puede generar experiencias de comunión intersubjetiva y solidaria, que dan cuenta del carácter comunitario que posee la esperanza y la responsabilidad inherente a la tarea de transformar el mundo.

Especial importancia adquiere la conciencia y la libertad como expresión de la subjetividad, cuando Alfaro la erige como la dimensión donde se inserta el Espíritu de Cristo por la Encarnación, en virtud de lo cual el hombre, y, por él, el mundo pasan a quedar cristofinalizados. 
giro antropológico propuesto por el Concilio Vaticano II, donde, mediante este eje articulador, establecerá una conexión entre el destino último del hombre y sus relaciones intramundanas, en su referencia a la naturaleza, a la historia, a los demás hombres y a Dios.

Ahora bien, en ese transcurrir, lo que se manifiesta condicionando tensionalmente gran parte de su reflexión es el paso de una concepción inmanente del origen de la conciencia -como coronación del dinamismo evolutivo de la materia-, al reconocimiento de la presencia de un factor divino como causa no empírica de la conciencia y de la libertad humana, generadoras de efectos cualitativos no predecibles en su relación con el mundo, y en este con su destino final.

De acuerdo a esto, y con el propósito de facilitar una lectura ordenada de este artículo, presentaré, en primer lugar, lo que el autor plantea en relación al origen divino de la subjetividad; luego intentaré mostrar las repercusiones que, según el autor, ejerce en el hombre la subjetividad como don. Finalmente, en tercer lugar, procuraré hacer visibles las tensiones presentes en el proceso reflexivo del autor, ante las cuales, en algunos casos, presentaré mi opinión personal; de ahí que esta tercera parte tenga el carácter de consideraciones finales conclusivas y posea una extensión mayor en relación a las anteriores.

\section{RESPECTO AL ORIGEN DIVINO DE SUBJETIVIDAD HUMANA}

\section{Antecedentes previos respecto al origen no natural de la subjetividad}

En plena década de los años setenta, Alfaro, basado en los aportes realizados por Teilhard de Chardin, hace una valoración positiva respecto a la relación que el autor francés establece entre evolución de la materia, conciencia y persona.

$\mathrm{Al}$ respecto, efectivamente, nuestro autor señala que la vida, al igual que la conciencia, sería parte de la tendencia inmanente, propia del universo, desde que se produjo la primera unión elemental de la materia. En específico, esta tendencia inmanente culmina en la personalización humana ${ }^{2}$, es decir, en el surgimiento de la conciencia, lo cual indica que el dinamismo natural del mundo tiende a su finalización en el hombre

2 Cf. J. Alfaro, Hacia una teología del progreso humano (Herder, Barcelona, 1974) 26-27; 52; 66-67. 
-muy probablemente por vía evolutiva, reafirmará con énfasis el autor años más tarde ${ }^{3}$ - como su interna razón de ser, como su sentidó .

Esto significa, en definitiva, que el surgimiento del hombre comporta una suerte de segunda creación, en virtud de la cual el mundo se abre a un proceso de desarrollo de expansión ilimitada orientado a una realidad de orden superior ${ }^{5}$, que ha de culminar con su retorno al Creador ${ }^{6}$.

Con todo, Alfaro señala en este período que la conciencia del ser personal del hombre es solo una infraestructura antropológica previa (potencia obediencial en términos clásicos), necesaria para la llamada al hombre a esperar en Cristo, y en este sentido, precisa, la apertura radical del hombre a la esperanza no es todavía la esperanza, ni siquiera es su llamada ${ }^{7}$.

Sin embargo, en una publicación correspondiente al año 1973, el autor va a indicar -en el marco de la relación entre naturaleza y gracia- que la autopresencia conciencial y la libertad creatural del hombre

3 Cf. J. Alfaro, "El hombre abierto a la revelación de Dios", en Revelación cristiana, fe y teología (Verdad e Imagen, Salamanca 1994), 18; J. Alfaro, "La cuestión del hombre y de Dios en la filosofía de I. Kant, L. Feuerbach y M. Heidegger", en De la cuestión del hombre a la cuestión de Dios (Sígueme, Salamanca 1997) 39.

4 Cf. J. Alfaro, Esperanza cristiana y liberación del hombre (Herder, Barcelona 1972) 165; 181; 193-194; J. Alfaro, Hacia una teología..., 42. Alfaro señala que el sentido del mundo radica en el hombre, en cuanto este constituye la orientación final hacia la cual aquel fue creado, a objeto de que por su acción, la creación del mundo sea completada, sirva a su progreso y reciba de él su destino (cf. ibíd. 55). En este sentido, para el autor, el hombre se constituye en socio de Dios. Cf. J. Alfaro, “Tecnopolis e cristianesimo", en La civiltà cattolica 2856 (1969), 546-547.

5 Que el aparecimiento del hombre en el mundo comporte, para Alfaro, una especie de segunda creación, significa que el mundo, en ausencia del hombre, tendría un dinamismo mecánico basado en un proceso cuyas leyes lo limitarían a un progreso cerrado e insuperable. En este sentido, el aparecimiento del espíritu humano abre al mundo, con su gran caudal de energía, a un proceso de desarrollo y potencialidad de ilimitada capacidad de expansión, orientado hacia una esfera de orden superior. Se trata, dice el autor, de una elevación del mundo a un porvenir carente de límites a causa de su participación de la potencia creativa ilimitada del hombre (cf. J. Alfaro, Hacia una teología..., 41; Esperanza cristiana y..., 181), cuyo núcleo lo constituye su conciencia espiritual (cf. Esperanza cristiana y..., 181). Esto le permite señalar a nuestro autor que el aparecimiento del hombre representa para el mundo el inicio de la era de su liberación (cf. J. Alfaro, “Tecnopolis e...”, 535), y que la tarea de transformar el mundo el hombre la ha recibido por el solo hecho de ser espíritu en el mundo, y no mediante un encargo mandatado por Dios. Cf. J. Alfaro, “Tecnopolis e ...", 535.

6 Cf. J. Alfaro, Hacia una teología..., 42.

7 Cf. J. Alfaro, Esperanza cristiana y..., 31. 
El origen divino de la subjetividad en la reflexión teológica de Juan Alfaro. | 99

como espíritu finito, constituyen el punto de inserción inmanente de la gracia $^{8}$, y por lo mismo se erigen como la dimensión nuclear fundamental en la que hay que profundizar -como problema antropológico- en pos de la comprensión de dicha inmanencia9. Para tal profundización, Alfaro transforma en pregunta aquello que ha constatado como propio de la creatura intelectual ${ }^{0}$ : “¿Lleva el hombre, en su misma condición de espíritu, una orientación apriórica hacia la visión de Dios y cuál es esta orientación?"11. En su abordaje, el autor señala los siguientes aspectos relativos a la subjetividad humana:

Reconociendo que el hombre existe solo bajo la gracia de Cristo -existencial crístico-, en virtud de lo cual está llamado desde lo más profundo de su espíritu a la comunión de vida con Dios y finalmente a Su visión, Alfaro indica que, desde la reflexión teológica, se puede des-

8 Cf. J. Alfaro, "El problema teológico de la trascendencia y de la inmanencia de la gracia”, en Cristología y Antropología (Cristiandad, Madrid 1973) 312.

9 Cf. J. Alfaro, "El problema teológico...", 317.

10 Cf. J. Alfaro, “El problema teológico...”, 311. La categoría creatura intelectual es tratada por Alfaro cuando aborda de manera explícita el problema teológico relativo a la inmanencia y la trascendencia de la gracia. Tal abordaje lo realiza en dos momentos separados por 16 años: El primer momento corresponde al año 1957 a través del artículo Trascendencia e inmanencia de lo sobrenatural. Aquí, Alfaro considera al hombre -en un sentido abstracto- como creatura intelectual, en cuanto existe en él capacidad de verdad y de bien en cuanto tales, y desde esta perspectiva lo diferencia -y en este análisis prescinde- del hombre histórico con sus aspectos existenciales provenientes, por un lado, del hecho de estar afectado por el pecado original, y, por otro, del hecho de estar destinado a la visión de Dios como su único fin último. Cf. J. Alfaro, "Trascendencia e inmanencia de lo sobrenatural", en Gregorianum 38 (1957), 8, nota 7.

El segundo momento corresponde al año 1973. Aquí el mencionado problema es abordado en El problema teológico de la trascendencia y de la inmanencia de la gracia, donde las notas distintivas, a diferencia del anterior, tienen sus referentes en el dato de la revelación -particularmente en los aspectos cristológicos y en la condición realhistórica del hombre proporcionados por el Concilio Vaticano II-, sustituyendo el referente metafísico clásico en el que la categoría creatura intelectual era analizada a base de criterios hermenéuticos abstractos, los cuales, en la época medieval, señala el autor, tendían a cosificar y a objetivar la relación del hombre al Dios de la gracia, soslayando la dimensión interna propia del hombre. Al respecto véase el análisis comparativo -ventajas y desventajas- que Alfaro realiza entre la categoría aristotélica naturaleza -usada, según él, por la mayoría de los teólogos medievales (salvo Santo Tomás) y postridentinos para referirse a la relación naturaleza-gracia- y la categoría creatura intelectual: J. AlfARO, “El problema teológico...”, 248-254. Cf. 314, nota 181.

11 J. Alfaro, "El problema teológico...", 317. 
cubrir en la existencia concreta del hombre la presencia de aquel núcleo fundamental-conciencia y libertad-como perteneciente a su estructura creatural-espiritual-equivalente a la categoría naturaleza ${ }^{12}-$, y, por ello mismo, como "presupuesto ontológico necesario (condición trascendental) para la posibilidad de la llamada del hombre por la gracia" ${ }^{13}$. En este sentido, tal presupuesto no puede ser considerado como efecto de la gracia; esta, si bien toca la conciencia del hombre, no se identifica con ella ${ }^{14}$, porque no es posible, indica, ubicar en un mismo plano de identidad "lo «experimentado vitalmente» con lo «natural»"15.

No obstante, y tal vez a causa de esa misma incompatibilidad de identidad entre la experiencia vital y la naturaleza, Alfaro señala un aspecto importante que impide, a partir de lo indicado, una interpretación rígida de la relación conciencia (naturaleza)-gracia que será necesario tener en consideración para comprender el desarrollo de su pensamiento relativo a la orientación apriórica del espíritu humano a la visión de Dios.

En concreto: si bien nuestro autor deja claramente establecido que la conciencia -en cuanto presupuesto necesario para la gracia- no puede ser efecto de ella, también deja claramente establecida la existencia de una frontera indeterminada en la relación entre ambas, causante de la imposibilidad de distinguir con seguridad -al interior de la experiencia vital concreta- aquello que pertenece propiamente a la estructura finita espiritual del hombre ${ }^{16}$.

Esta frontera indeterminada se originaría por la presencia apriórica de Dios en la conciencia como término último real del dinamismo in-

12 Cf. J. Alfaro, “El problema teológico...”, 317, nota 183; 338. Según Alfaro, esta categoría, para K. Rahner, equivaldría a "un «concepto-residual» que sustrae la dimensión básica de la existencia concreta del hombre, pecador o justificado, pero en todo caso llamado por la gracia a la visión de Dios". J. Alfaro, "El problema teológico...”, 338.

13 J. Alfaro, "El problema teológico...”, 317, nota 183. Cf. 338; 342. En virtud de esto, para Alfaro, tendría sentido una hipotética situación de progreso indefinido para el hombre: "En esta situación de progreso indefinido no carecería de razón de ser el «deseo natural» de ver a Dios, pues seguiría siendo siempre la condición trascendental de la misma actividad intelectivo-volitiva natural del hombre".

J. Alfaro, "El problema teológico...", 334, nota 223.

14 Cf. J. Alfaro, "El problema teológico...", 317, nota 183.

15 J. Alfaro, "El problema teológico...", 317, nota 183.

16 Cf. J. Alfaro, “El problema teológico...”, 334, nota 223. 
telectivo volitivo, que orienta constitutivamente a la espiritualidad -a modo de deseo natural ${ }^{17}$ - hacia el trascendente, sin poderla alcanzar por sí misma finalmente, y en la que está implicada un conocimiento atemático-aconceptual de él-experiencia de precomprensión de sí mismo y del trascendente en su relación mutua-, causante de la inquietud existencial al interior de la misma autopresencia conciencial, que impone la pregunta acerca del sentido que tiene la existencia humana -en su dimensión individual y colectiva- y la del mundo, lo cual inevitablemente ubica al hombre de cara al misterio de Dios ${ }^{18}$.

Por otra parte, en este mismo período -año 1972-, probablemente a causa de la profundización en la concepción que Marx y Bloch tienen del hombre y de la historia, Alfaro se plantea la posibilidad de que el ser personal del hombre tenga su fundamento en el Ser Personal Trascendente y no en la evolución cósmica inmanente, cuyo resultado sería la fatalidad de un dinamismo impersonal ${ }^{19}$.

17 Con el propósito de despejar cualquier malentendido que la categoría deseo pueda representar, Alfaro precisa lo siguiente:

1. Con ella se hace referencia a "la misma estructura ontológica apriórica ('in actu primo') de las facultades intelectivo-volitivas del hombre, en virtud de la cual están internamente necesitadas (anteriormente a todo acto de pensar o querer) a tener que buscar indefinidamente a Dios mientras no reciban la manifestación inmediata de Dios en sí mismo, y a no poder buscar ulteriormente una vez recibida la visión de Dios. Esta necesidad apriórica se actúa, no en algún acto especial de pensar o desear la visión de Dios, sino en el inevitablemente indefinido siempre adelante de toda actividad intelectivo-volitiva del hombre, guiada por la pregunta de Dios; se actuará también en el definitivo no buscar ulteriormente, que tendrá lugar en la visión”. J. Alfaro, “El problema teológico...”, 323. Cf. 339, nota 236.

2. El deseo se denomina natural, "no tanto porque pertenece a la 'naturaleza' misma del hombre como creatura-intelectual, sino sobre todo por la necesidad apriórica que imprime a la actividad intelectivo-volitiva del espíritu humano. Puede llamarse incondicionado precisamente en cuanto es apriórico, es decir, normativo de la actividad del espíritu y no normado por ella. Pero es 'condicionado' respecto a su término (la visión de Dios), que el hombre no puede lograr por su dinamismo natural, sino únicamente recibir como gracia absoluta de Dios en sí mismo". J. Alfaro, "El problema teológico...", 323-324. En este sentido, concluye Alfaro, la visión de Dios constituye un término absolutamente posible para el espíritu finito. Cf. J. Alfaro, “El problema teológico...”, 324.

18 Cf. J. Alfaro, "El problema teológico...", 319-325; J. Alfaro, "Foi et existence", en Nouvelle Reveu Thelogique, 6 (1968) 578.

19 “QQué es el hombre?, ¿qué soy yo? ¿Soy simplemente el resultado fatal del dinamismo impersonal de la evolución cósmica, o mi existencia como ser personal y libre 
En este sentido, en una publicación correspondiente al año 1978, va a afirmar que la conciencia y la libertad, en cuanto fundamento de la esperanza ilimitada, constituye el núcleo espiritual originario de la persona, el cual "es irreductible a la naturaleza y a toda colectivización de lo humano, pues lo auténticamente humano no es lo colectivo sino lo comunitario, que supone y mantiene lo personal" ${ }^{20}$.

2. Conciencia y libertad, fundamento del ser personal del hombre, cuyo origen no puede ser explicado suficientemente solo a partir de los procesos naturales

Considerando la índole exclusivamente interior de la conciencia y su carácter no empírico, Alfaro da un paso notable en relación a la reflexión relativa a la cuestión del origen de la conciencia y de la libertad.

Efectivamente, sin perjuicio de la hipótesis evolucionista, planteada por él como muy probable en relación al origen del hombre, esta no permite, sin embargo, explicar que, en última instancia, el proceso material implicado en la evolución, cuyos resultados están supeditados a la verificación empírica, sea a su vez y por sí mismo la causa del surgimiento de la conciencia. En este sentido, dice el autor, la inaccesibilidad a la verificación empírica, entendida como cualidad fundamental de la conciencia, impide atribuir solo a los procesos de la materia la causa de su origen ${ }^{21}$. De hecho, precisa, el estado actual del conocimiento cientí-

debe ser un fundamento personal trascendente, distinto del dinamismo evolutivo inmanente de la materia?”. J. Alfaro, Esperanza cristiana y..., 225.

20 J. Alfaro, Esperanza cristiana y..., 122.

21 "La índole, exclusivamente interior, de la conciencia impone la cuestión de su origen. Admitida, como altamente probable, la hipótesis evolucionista, la cuestión se presenta así: ¿puede ser la materia, por sí sola, el origen último de la conciencia? ¿Se puede explicar la conciencia, en última instancia, como mero resultado del solo proceso de la materia? La respuesta deberá tener en cuenta que un proceso de la materia tendrá que ser un proceso material y por eso empíricamente verificable. Ahora bien, la conciencia no pertenece a lo empíricamente verificable. La materia es esencialmente realidad sensible. Sensibles son sus procesos y los resultados de ellos. La cualidad fundamental de la conciencia, es decir, su inaccesibilidad a la verificación empírica, no permite explicar su origen con los procesos de la materia”. J. Alfaro, "El hombre abierto a la revelación de Dios", en Revelación Cristiana, Fe y Teología (Verdad e Imagen, Salamanca 1994) 27. Cf. J. Alfaro, "La cuestión del hombre en su relación al mundo", en De la cuestión del hombre a la cuestión de Dios (Sígueme, Salamanca 1997) 201-202; 210-211; J. Alfaro, "Epílogo", en De la cuestión del hombre a la cuestión de Dios (Sígueme, Salamanca 1997), 273. 
fico presenta un vacío inmenso, no resuelto, en el proceso de transición que va desde los homínidos al hombre ${ }^{22}$.

Al mismo tiempo, considerando que la libertad constituye una dimensión que es "inmanente a la conciencia" 23 , y que juntas conforman el yo personal, es decir, la subjetividad humana ${ }^{24}$, el planteamiento respecto a su origen, obviamente va a estar estrechamente vinculado -dándole mayor claridad, incluso- al del origen de la conciencia ${ }^{25}$.

El hecho de que el fundamento último de la conciencia y de la libertad, como constitutivos del ser personal del hombre, no pueda explicarse suficientemente considerando los meros procesos de la naturaleza ${ }^{26}$, se debe, precisamente, a que la conciencia y la libertad "trascienden el funcionamiento neuronal del cerebro humano" 27 , constituyéndose, por ello, en el fundamento causal de la diversidad cualitativa y de la insuperable distancia existente entre hombre y animal ${ }^{28}$.

22 J. Alfaro, "La cuestión del hombre en su relación al mundo", 201-202. Cf. 202, nota 2; W. H. Thorpe, Naturaleza animal y naturaleza humana (Madrid 1980), 301; 269, citada por Alfaro en "La cuestión del hombre en su relación al mundo", 202, nota 2.

23 J. Alfaro, "El hombre abierto a...", 20.

24 Cf. J. Alfaro, "La cuestión del hombre en su relación al mundo", 211.

25 "La reflexión sobre la imposibilidad del salto, desde los procesos materiales sensibles de la naturaleza a la interioridad de la conciencia, gana en claridad cuando se trata del salto de los procesos naturales a los actos libres. La decisión de la libertad rompe todos los esquemas pensables de un proceso meramente natural, es decir, controlable mediante la experiencia empírica. El devenir cósmico no puede ser el origen de la libertad humana". J. AlfARO, "La cuestión del hombre en su relación al mundo", 212, nota 11. Cf. 214, nota 13; J. Alfaro, "El hombre abierto a...”, 29-30.

26 Cf. J. Alfaro, "El hombre abierto a...", 30; J. Alfaro, "La cuestión del hombre en su relación al mundo", 216.

27 J. Alfaro, "La cuestión del hombre en su relación al mundo", 212, nota 12.

28 En efecto, al respecto Alfaro indica que "varios científicos modernos de fama mundial (entre ellos los premios nobel W. Penfield y J. Eccles) han notado la distancia insuperable entre los animales y el hombre: una diversidad cualitativa proveniente de que solamente el hombre tiene conciencia y libertad, que trascienden el funcionamiento neuronal del cerebro humano. No se puede considerar la conciencia como idéntica a los fenómenos neuronales: se trata de una entidad emergente respecto al aparato cerebral: los fenómenos mentales trascienden claramente los fenómenos de la fisiología y de la bioquímica ( $R$. W. Sperry, "A modified Concept of Conciouness", Psicological Review [1969], 149-150). Con el hombre ha surgido una distinción radical entre la vida y la mente. Aquella es cuestión de química y física; esta, escapa a la química y a la física (T. Dobzhansky, "Evolución del género humano», Evolución, Barcelona [1980], 439; 448; 451). No hay una parte definida 
Esto le permite al autor concluir la existencia de un plus ${ }^{29}$ de dinamismo - proveniente de una realidad trascendente y personal, identificable con Dios- en el movimiento procesal de la materia que, en relación al hombre, se constituye en la instancia última que funda su ser personal ${ }^{30}$ a través de la conciencia y de la libertad.

\section{RESPECTO A LAS REPERCUSIONES EN EL HOMBRE DEL ORIGEN DIVINO DE LA SUBJETIVIDAD}

1. Dios como fundamento de sentido existencial para el hombre, que le interpela a una respuesta de carácter mostrativo

Mediante el plus señalado, el ser personal se hace receptor de la esperanza ilimitada como apertura hacia un más allá de los límites inmanentes de la

del cerebro que corresponda al yo. No hay ningún factor inmanente al funcionamiento neuronal del cerebro que sea determinante para la toma de decisiones. La mente autoconsciente es apta para actuar sobre los mecanismos cerebrales y responsable de las decisiones dictadas por estos (K. Popper - J. Eccles, "El yo y su cerebro», Barcelona [1980], 310; 331; 407). La mente es una esencia distinta y precisa: las acciones de los mecanismos cerebrales, reflejos o automáticos, son numerosas y complejas; pero lo que realiza la mente es completamente distinto, y de ello no es responsable ningún mecanismo neuronal que yo alcance a descubrir (W. Penfield, "El misterio de la mente», Madrid [1977], 90; 99). La conciencia de la mismidad, que es una conciencia autorreflexiva, está ausente de los animales. El hombre es capaz de "percatarse de si mismo" (W. H. Thorpe, "Naturaleza animal y naturaleza humana", Madrid [1980], 302; 352; 354)". J. Alfaro, "La cuestión del hombre en su relación al mundo", 212, nota 12. Para una mirada más exhaustiva respecto a estos puntos, Alfaro remite, en esta misma nota, a J. L. RUIZ DE LA PEÑA, Las nuevas antropologías (Sal Terrae, Santander 1983), 119-130; 174-199.

29 J. Alfaro, "El hombre abierto a...", 30; J. Alfaro, "La cuestión del hombre en su relación al mundo", 216.

30 "Si (como se ha mostrado) los procesos meramente naturales no son suficientes para explicar el ser personal del hombre (conciencia y libertad), y por otra parte todo el proceso evolutivo ha culminado de hecho en el hombre, se debe concluir que a lo largo de todo el proceso ha habido ya un plus de dinamismo respecto a las posibilidades procesuales de la sola materia y que la materia ha tenido que recibir este plus de una realidad trascendente. Si la naturaleza lo ha recibido, quiere decir que depende de esa realidad trascendente: la realidad trascendente y personal que en último término funda el ser del hombre, es también fundamento respecto a la naturaleza; no puede menos de llevar un nombre absolutamente singular: Dios". J. Alfaro, "El hombre abierto a...", 30. Cf. J. Alfaro, "La cuestión del hombre en su relación al mundo", 216. 
muerte y de la historia ${ }^{31}$, en virtud de lo cual el hombre no puede ser reducido a un mero instrumento impersonal y anónimo en el devenir de dicha historia. De este modo, para el autor, tal plus divino viene a constituirse, en definitiva, en instancia portadora de sentido existencial para el hombre ${ }^{32}$.

En efecto, esto puede verificarse en tanto que, del análisis de la cuestión del hombre a partir de la relación existente entre él y el mundo -de carácter reflexivo mostrativo, no demostrativo ${ }^{33}$-, surge simultánea y conectivamente la cuestión de Dios como "Realidad Fundante, Trascendente, Personal" 34 y "como dotada de sentido" 35 , que interpela a una respuesta dirigida a la inteligencia y a la libertad.

Esta respuesta, en coherencia con el llamado, no podrá, por cierto, ser de carácter demostrativo, es decir, consecuencia de una evidencia constringentemente lógica, excluyente de la libertad, sino que tendrá que ser necesariamente una mostración que implique el acto total de comprensión y opción, de conocer y $\operatorname{decidir}^{36}$, a base de una actitud

31 "El Porvenir último, absoluto, de la esperanza-esperante y del devenir histórico se llama Dios. Este Dios no es solamente el término del esperar humano, sino también su origen; es el Dios que suscita en el hombre la esperanza ilimitada, al crearlo como persona (conciencia y libertad) y llamarlo así a esperar más allá de la historia y de la muerte". J. Alfaro, "Epílogo", 277.

32 Cf. J. Alfaro, "El hombre abierto a...”, 31; "La cuestión del hombre en su relación al mundo", 216.

33 Ciertamente, el análisis del que emerge el carácter significativo de la cuestión de Dios, se ha basado, dice Alfaro, en una reflexión que no ha comportado "una «demostración», sino una «mostración», porque en ella juega un papel decisivo la libertad como tarea y responsabilidad, y la responsabilidad no se la puede conocer sino reconociéndola, es decir, en un conocimiento -comprometido- que implica la opción”. J. AlfARO, "El hombre abierto a...”, 31. En este punto, puede apreciarse en el pensamiento de Alfaro la recurrencia a una distinción entre verificación demostrativa-objetiva-empírica y verificación mostrativa-subjetiva-testimonial (cf. J. Alfaro, "El hombre abierto a...", 31; 16-17; J. Alfaro, "La cuestión del sentido y el sentido de la cuestión”, en Gregorianum 66 (1985) 397), que conlleva un lenguaje de tipo significativo. Cf. la crítica que al respecto Alfaro le hace a Wittgenstein: J. Alfaro, "Ludwig Wittgenstein ante la cuestión del sentido de la vida", en Gregorianum 67 (1986), 735-743.

34 J. Alfaro, "El hombre abierto a...”, 30. Cf. 62; J. Alfaro, "La cuestión del hombre en su relación al mundo", 216; J. Alfaro, "Epílogo", 283.

35 J. Alfaro, "El hombre abierto a...", 31. Cf. "La cuestión del hombre en su relación al mundo", 216.

36 Cf. J. Alfaro, "La cuestión del hombre en su relación al mundo", 216-217; J. ALFARO, "La cuestión del hombre en las relaciones interpersonales", en De la cuestión 
existencial de reconocimiento y aceptación de Dios como gracia absoluta, imposible de disponer humanamente, ante Quien solo cabe la espera, confianza y abandono ${ }^{37}$.

Ahora bien, desde esta perspectiva, el acto de creer se identifica con la decisión de dar sentido a la vida, poniendo a Dios como su fundamento nuclear, a partir de motivos que suficientemente la justifican como una opción auténticamente humana -no ilusoria- asumida desde la inteligencia y la libertad ${ }^{38}$.

2. La condición de contingencia, de responsabilidad y de orientación al futuro que posee la existencia humana y que pone en evidencia el carácter de don que posee la libertad

Dada la experiencia del hombre de estar en posesión de una libertad que forma parte de la misma experiencia de su existir, y que esta existencia no ha tenido su origen en él, sino que la vive como una existencia recibida, como puesto en ella ${ }^{39}$, se puede concluir que tal libertad ha sido recibida por el hombre como don.

del hombre a la cuestión de Dios (Sígueme, Salamanca 1997), 237; J. Alfaro, "El devenir histórico y su sentido", en De la cuestión del hombre a la cuestión de Dios (Sígueme, Salamanca 1997), 270; J. Alfaro, “Epílogo”, 282.

37 Cf. J. Alfaro, "El hombre abierto a la revelación de Dios", 62-63; J. Alfaro, Esperanza cristiana y..., 55; 164; 214; J. Alfaro, "Perspectivas para una teología sobre la fe", en Revelación cristiana, fe y teología (Verdad e Imagen, Salamanca 1994), 112; J. Alfaro, "Epílogo", 282-283; 285; J. Alfaro, "Foi et existence", 569.

38 Cf. J. Alfaro, "La cuestión del hombre en su relación al mundo", 216-217; J. AlfARO, "La cuestión del hombre en las relaciones interpersonales", 237. En este sentido, para el autor, en términos estrictos, "la existencia de Dios no se demuestra: se cree, es decir, se afirma en una decisión (convicción) suficientemente motivada para que sea opción auténticamente humana" (J. Alfaro, "La cuestión del hombre en su relación al mundo", 217). De manera más acotada, esto significa que «toda opción no-normada, no-motivada, sería arbitraria, carente de razón y de razones, sin sentido y, en el fondo, sin auténtica libertad; ilusión de libertad». J. Alfaro, "La cuestión del hombre en su relación al mundo", 226. Cf. J. Alfaro, "El problema teológico...", 303; 310; J. Alfaro, "Foi et existence", 570; J. Alfaro, "Revelación y fe", en Cristología y Antropología, (Cristiandad, Madrid 1973) 383; 390-391; 394; J. Alfaro, "Teología, Filosofía y Ciencias humanas", en Gregorianum 55 (1974) 214; J. Alfaro, "Perspectivas para una teología sobre la fe", 111.

39 Cf. J. Alfaro, "El hombre abierto a...", 29; J. Alfaro, "La cuestión del hombre en su relación al mundo", 213. Se aprecia en este punto la influencia en Alfaro del pensamiento filosófico de M. Heidegger. Cf. M. Heidegger, "Sein und Zeit", 134135; 193-198; 377-378; "Vom Wesen des Grundes", 46-54, citado por Alfaro en "La 
En virtud de este don, precisa Alfaro, el hombre queda interpelado para (libertad para) llevar a cabo su realización personal a través de la transformación del mundo ${ }^{40}$ y a través del cumplimiento de la tarea fundamental de dar sentido a su vida ${ }^{41}$.

Esto pone en presencia de una estrecha relación en el hombre, entre el origen divino de la libertad y la condición de sujeto contingente y responsable propia de él, en su orientación al futuro.

Veamos más de cerca esta relación:

A. Desde la perspectiva de la relación entre la libertad como don, la responsabilidad, y la contingencia radical del sujeto.

La capacidad de ser interpelado, señala Alfaro, es un constitutivo que pertenece a la estructura ontológica del hombre, inherente a su libertad-responsabilidad ${ }^{42}$.

Ahora bien, esta experiencia del hombre de estar permanentemente cuestionado, interpelado, muestra que, en última instancia, el fundamento de su existencia no radica en él ni en la naturaleza, lo que pone de manifiesto su radical contingencia y que dicho fundamento está "en la Realidad Fundante Trascendente Personal"43, "que es designada con un nombre propio y único; Dios" ${ }^{34}$.

A partir de esto se explican tres situaciones estrechamente conectadas:

Una de ellas se refiere a la responsabilidad de la libertad, que alcanza su radicalidad e incondicionalidad más profunda ante la gracia de la

cuestión del sentido y el sentido de la cuestión", 390, cita 6; J. AlFARO, "El hombre abierto a...", 13; 22, cita 6 .

40 Cf. J. Alfaro, "El hombre abierto a...”, 29; 62.

41 Cf. J. Alfaro, "La cuestión del hombre en su relación al mundo", 213; J. Alfaro, "Epílogo", 273.

42 Cf. J. Alfaro, "El hombre abierto a...", 30; J. Alfaro, "La plenitud de la revelación cristiana: su interpretación teológica”, en Revelación cristiana, fe y teología (Verdad e Imagen, Salamanca 1994) 195; J. Alfaro, "La cuestión del hombre en su relación al mundo", 215-216; J. Alfaro, "La cuestión del hombre en las relaciones interpersonales", 225.

43 J. Alfaro, "El hombre abierto a...", 30. Cf. 62; J. Alfaro, "La cuestión del hombre en su relación al mundo", 215.

44 J. Alfaro, "La cuestión del hombre en su relación al mundo", 215. Cf. J. Alfaro, "El hombre abierto...", 62; J. Alfaro, "Epílogo", 274; 283. 
autodonación de Dios, dado que en ella está en juego la definitividad de la existencia del hombre ${ }^{45}$.

Otra situación es la posibilidad del hombre de conocer a Dios mediante su opción fundamental, en la cual lo reconoce como "Fundamento último de su libertad-responsabilidad" ${ }^{46}$.

Una última situación la constituye el riesgo -a causa de la creaturalidad propia de la libertad responsable- de una respuesta negativa del hombre a la llamada presente en la autodonación divina, por la cual podría rehusarse a recibir la gracia de la salvación. Tal respuesta constituiría un autojuicio, que en este caso resultaría en autoperdición $n^{47}$.

B. Desde la perspectiva de la relación entre la libertad como don, la responsabilidad y la orientación al futuro del sujeto.

El análisis relativo a la cuestión del origen de la libertad, tendría que realizarse, concluye Alfaro, en estrecha relación con la apriórica orientación hacia el futuro, propia de la libertad para del sujeto ${ }^{48}$.

En este sentido, habría que entender el "de dónde viene y hacia dónde va" $^{\text {49 }}$ como dos semblantes de una misma realidad, lo cual hace evidente la existencia de una identidad entre el " "origen de» y el "término hacia»" 50 de la libertad, y, consecuentemente, que la misma realidad que suscita y mantiene su mencionada orientación es también la causa de su origen ${ }^{51}$.

Por su parte, y en coherencia con lo anterior, el análisis del origen de la libertad desde la perspectiva de la responsabilidad, ha de tener presente, para su comprensión, lo siguiente:

45 Cf. J. Alfaro, "La plenitud de la revelación cristiana...", 195-196; J. Alfaro, Esperanza cristiana y..., 110.

46 J. Alfaro, "Epílogo", 274.

47 Cf. J. Alfaro, "La plenitud de la revelación cristiana...", 196; J. Alfaro, Esperanza cristiana y..., 110, nota 201; J. Alfaro, "Actitudes fundamentales de la existencia cristiana", en Cristología y Antropología (Cristiandad, Madrid 1973) 414.

48 Cf. J. Alfaro, "El hombre abierto a...", 36; 37; J. Alfaro, "La cuestión del hombre en su relación al mundo", 213.

49 J. Alfaro, "El hombre abierto a...”, 29. Cf. J. Alfaro, "La cuestión del hombre en su relación al mundo", 214.

50 J. Alfaro, "El hombre abierto a...”, 29; J. Alfaro, "La cuestión del hombre en su relación al mundo", 214.

51 Cf. J. Alfaro, "El hombre abierto a...", 29; J. Alfaro, "La cuestión del hombre en su relación al mundo", 213-214. 
Que la orientación hacia el futuro del hombre, implica su realización como persona a través del ejercicio de su libertad en las acciones destinadas a la transformación del mundo ${ }^{52}$, lo cual supone la existencia de un ser personal -un alguien del mismo nivel ontológico y axiológico- a quien, en un contexto de relación interpersonal, es decir, de encuentro de libertades, pueda dar cuenta razonable de dichas acciones libres ${ }^{53}$.

A partir de lo señalado el autor plantea lo siguiente:

En primer lugar, plantea la existencia de una suerte de connaturalidad entre la responsabilidad humana y un ser personal trascendente, ante el cual el hombre ha de ser responsable de llevar a cabo la mencionada tarea relativa a la transformación del mundo: se trata del "ante Quien" ${ }^{4}$ -como realidad radicalmente distinta a la naturaleza impersonal ${ }^{55}$-, que

52 Cf. J. Alfaro, "El hombre abierto a...", 29.

53 Alfaro explicita este punto de las siguientes maneras:

1. La "dimensión formal de la responsabilidad, constitutiva de la dimensión dialógica del hombre" (J. Alfaro, "La cuestión del hombre en su relación al mundo", 214), implica para este un "encuentro interpersonal entre un "yo" llamado a dar razón de sus actos libres y un "tú» que le pide responder a esta llamada. La responsabilidad no puede tener lugar sino en la relación entre mi ser personal y el ser personal del otro. No tiene sentido hablar de responsabilidad sino dentro de una relación interpersonal, entre persona y persona, entre libertad y libertad". J. Alfaro, "La cuestión del hombre en su relación al mundo", 214.

2. "La libertad de cada hombre es realmente responsable ante la dignidad personal (conciencia y libertad) de los otros; pero también viceversa, los otros son responsables ante mi ser personal, ante mí como persona; es, pues, una responsabilidad mutua, común de todos, igualmente esencial y constitutiva de cada uno como persona: la del uno y la del otro (todas) están al mismo nivel ontológico y axiológico. Por consiguiente, la libertad responsabilidad del otro no es el fundamento último de la mía, ni viceversa". J. Alfaro, "La cuestión del hombre en su relación al mundo", 214.

54 J. Alfaro, "El hombre abierto a...", 62; J. Alfaro, "La cuestión del hombre en su relación al mundo", 214; J. Alfaro, "La cuestión del hombre en las relaciones interpersonales", 238; J. Alfaro, "Epílogo", 285; 286.

55 En este punto, Alfaro distingue entre responsabilidad de y responsabilidad ante. En efecto, al respecto señala que "el hombre es responsable de la transformación de la naturaleza, pero no es responsable ante la naturaleza. No se puede ser responsable ante una realidad impersonal como es la naturaleza, sino solamente ante un ser personal". J. Alfaro, "El hombre abierto a...", 29. Cf. J. Alfaro, "La cuestión del hombre en su relación al mundo", 214; J. Alfaro, "La cuestión del hombre en las relaciones interpersonales", 238; J. Alfaro, “Epílogo”, 274; 284. 
se identifica con la misma realidad última, fundamento común de la libertad responsable de todos y cada uno de los hombres ${ }^{56}$.

Esto significa -en síntesis- que, así como origen de y término hacia constituyen una idéntica realidad, aquí también convergen en una misma realidad personal-trascendente "el de dónde y el ante quien" ${ }^{57}$ de la responsabilidad $^{58}$.

En segundo lugar, plantea la existencia de una relación de mutua inseparabilidad entre la responsabilidad, la esperanza-esperante y la libertad humana en su orientación hacia la trascendencia.

En efecto, únicamente es posible la responsabilidad del hombre "en cuanto su esperanza trasciende todo porvenir intrahistórico: la esperanza no puede tener lugar sino en una libertad no-fundada en sí misma y, por eso, responsable. Responsabilidad y esperanza de la libertad son correlativas, y al mismo tiempo relativas a su común y trascendente Origen Fundante y Porvenir Absoluto, Dios" ${ }^{\text {59. }}$

56 Cf. J. Alfaro, "La cuestión del hombre en su relación al mundo", 215; J. Alfaro, "Epílogo", 274; 285.

57 J. Alfaro, "El hombre abierto a...", 29.

58 En relación a esto, el autor señala lo siguiente:

1. Respecto a la identidad existente entre el de dónde y el ante quién: “¿De dónde proviene (en última instancia) la responsabilidad del hombre, ante quién es (en último término) responsable? También en esta segunda formulación el de dónde y el ante quién tendrán que ser la misma realidad: la realidad última, que hace al hombre responsable". J. Alfaro, "El hombre abierto a...", 29. Cf. J. Alfaro, "La cuestión del hombre en su relación al mundo", 214.

2. Respecto al carácter personal-trascendente del fundamento último de la libertad responsable: Precisa que es "trascendente respecto a toda realidad del mundo y del hombre, que no pueden explicar el «de dónde» de la libertad; personal, porque solamente ante un ser personal puede tener sentido la responsabilidad (libertad) del hombre. Más aún, trascendente precisamente en cuanto personal, pues solamente en cuanto persona puede trascender absolutamente la naturaleza (en su impersonalidad) y al hombre (en su libertad)". J. Alfaro, "El hombre abierto a...", 30. Cf. J. Alfaro, "La cuestión del hombre en su relación al mundo", 215; 214, nota 13; J. Alfaro, "Epílogo", 282-283. "Perspectivas para una teología sobre la fe", 112; J. Alfaro, "El devenir histórico y su sentido", 269. 
Ello significa que en relación a la cuestión de Dios, la actitud propia del hombre ha de estar constituida por la disponibilidad y entrega al ante Quien, al que solo puede aguardar de manera plenamente confiada ${ }^{60}$.

Ahora bien, dentro de esta actitud de disponibilidad, la cualidad humana de atención y de escucha respecto a la imprevisible iniciativa divina, se manifiesta como un constitutivo esencial de la responsabilidad ${ }^{61}$.

Finalmente, en tercer lugar, Alfaro plantea la imposibilidad de que los procesos naturales, a partir de sí mismos, puedan dar el salto cualitativo hacia el surgimiento de la acción libre del sujeto ${ }^{62}$. Esta acción, en efecto, es capaz de romper todo proceso natural predecible, razón por la cual "el devenir cósmico no puede ser ni el «de dónde» último ni el «hacia dónde» último de la libertad"63.

\section{RESPECTO A LAS TENSIONES Y CONSIDERACIONES FINALES}

Señalaba al final de la introducción de este trabajo que el transcurso que va de una concepción inmanente del origen de la conciencia-como coronación del dinamismo evolutivo de la materia-, al reconocimiento de la presencia de un factor divino como causa no empírica de la conciencia y de la libertad humana, generadoras de efectos cualitativos no predecibles en su relación con el mundo, y en este con su destino final, condiciona la reflexión que Alfaro realiza acerca de la subjetividad entendida como el eje que articula su discurso antropoteológico. Esto, en efecto, deja en evidencia que la evolución de su pensamiento en este punto ha estado marcada por tensiones intelectuales que explicarían la presencia de un cierto tono de ambigüedad en su postura respecto a la calidad -natural o no- del agente interno que posibilita la apertura del hombre a la plenitud y a la consecución de esta.

Ciertamente, dichas tensiones y ambigüedades se hacen visibles desde el inicio de su trabajo académico a propósito, por ejemplo, de la cuestión acerca de la existencia o no de un apetito innato respecto a la visión de Dios, lo que se verá reflejado en el debate relativo a la posibilidad de un nexo de necesidad interna entre la creaturalidad espiritual del

\footnotetext{
60 Cf. J. Alfaro, “Epílogo”, 286.

61 Cf. J. Alfaro, “Epílogo”, 286.

62 Cf. J. Alfaro, "El hombre abierto a...”, 29-30.

63 J. Alfaro, "El hombre abierto a...", 30.
} 
hombre y su destino a la divinización en dicha visión, que dará sentido a su propuesta basada en el existencial crístico $^{64}$.

1. En relación a la cuestión acerca de la existencia o no de un apetito innato respecto a la visión de Dios

La subjetividad como cuestión de fondo es posible percibirla ya en el contexto de la reflexión que Alfaro realiza en relación al problema teológico de la trascendencia y de la inmanencia de la gracia.

En este contexto, la inquietud teológica principal del autor queda ya de manifiesto en su trabajo doctoral publicado en 1952, que incorpora dos publicaciones previas realizadas por él en el marco de ese mismo trabajo. En la página introductoria inicial de este, plantea el problema respecto a la relación existente entre las perfecciones sobrenaturales y la naturaleza. En concreto, el problema podría formularse a través de la siguiente pregunta: ¿Cuál es la actitud ontológica de la naturaleza respecto a lo sobrenatural?

Según Alfaro, entre la naturaleza y las perfecciones de orden sobrenatural ha de haber cierta proporción ontológica, debido a que tales perfecciones, si bien pertenecen a un orden superior a la naturaleza, comportan respecto a esta un efecto perfeccionador intrínseco y vital. En este sentido, la visión de Dios, al constituir la perfección suprema de la naturaleza racional, a esta solo le cabe apetecerla.

Ahora bien, el problema se agudiza, según nuestro autor, si se considera la gratuidad de dichas perfecciones. Es decir, que junto con ser un complemento conveniente para la naturaleza, en virtud de lo cual se refleja esa cierta proporción ontológica entre ambas realidades (naturalsobrenatural), no obstante ello, tales perfecciones no constituyen una exigencia ontológica, por cuanto tienen un carácter gratuito.

A mi entender, este problema se hace fuertemente patente a partir del descubrimiento que el autor hace del pensamiento de Cayetano en esta materia. De hecho, una lectura simple de su investigación doctoral, refleja -como él mismo lo deja ver en las palabras que dirige al lector al

64 Para Alfaro, solo a partir de la Encarnación, el hombre, en virtud de la gracia de Cristo, de finalizable respecto a la visión de Dios, ha pasado a quedar finalizado en ella. La riqueza e importancia que comporta para el autor la categoría existencial crístico, es tratada explícitamente en la tercera parte de mi tesis doctoral, de la cual este artículo es una pequeña parte. 
inicio de su obra- que, sin perjuicio del carácter histórico teológico que ella tiene, la motivación central radica en el planteo del mencionado Cayetano, lo cual queda ratificado en las dos primeras páginas introductorias, cuando Alfaro cita a E. de Lubac como quien, en su obra Surnaturel, ha reconocido en Cayetano una postura innovadora en relación al camino tradicional que había seguido el pensamiento teológico tomista, respecto a la relación entre lo natural y sobrenatural ${ }^{65}$. También se hace manifiesta esta centralidad motivacional en los dos artículos contemporáneos a su investigación -productos de ella- donde el eje articulador es precisamente el planteamiento de Cayetano ${ }^{66}$.

Según lo que señala Alfaro, Cayetano, en el siglo XVI, rompe con la postura que durante tres siglos habían mantenido, en general, los teólogos tomistas a favor de la existencia de un apetito innato respecto a la visión de Dios.

En específico, de esta manera sintetiza Alfaro el planteamiento de Cayetano en este punto: "Si las perfecciones de orden sobrenatural no son debidas a la naturaleza, si no tienen que serle necesariamente comunicadas (si pudieron no ser), la naturaleza racional no puede tener un apetito innato de la visión de la esencia divina y, en general, de lo sobrenatural. Porque un apetito natural no puede existir en vano: para que no exista en vano, la perfección, que es su término, tiene que ser. Si, pues, existiera en la naturaleza racional un apetito innato de lo sobrenatural, lo sobrenatural tendría que ser: de lo contrario podría frustrarse definitivamente un apetito natural. El apetito innato incluye, según Cayetano, una exigencia ontológica de su objeto: la razón de ello está en que no puede existir en vano, quedando definitivamente frustrado de su objeto. Por consiguiente no existe en la naturaleza racional un apetito innato de la visión de la esencia divina: no puede apetecerse naturalmente, sino lo que está al alcance de las fuerzas de la naturaleza. El punto fundamental de esta deducción de Cayetano está en el principio filosófico de que, para que un apetito innato no exista en vano, su objeto tiene que ser, le

65 Cf. J. Alfaro, Lo natural y lo sobrenatural. Estudio histórico desde Santo Tomás hasta Cayetano (1274-1534), (Matriti, Madrid, 1952).

66 Cf. J. Alfaro, "Posición de Cayetano en el problema de lo sobrenatural. Su crítica a la teoría de Escoto", en Archivo Teológico Granadino 12 (1949) 49-160; J. Alfaro, "La gratuidad de la visión intuitiva de la esencia divina y la posibilidad del estado de naturaleza pura según los teólogos tomistas anteriores a Cayetano", en Gregorianum 31 (1950) 63-99. 
es naturalmente debido: en consecuencia, no puede haber apetito innato, sino de lo que es posible mediante las fuerzas naturales.

Solamente mediante la divina revelación podemos saber que la visión de Dios es nuestro último fin: la razón de ello está en la sobrenaturalidad y gratuidad de tal fin: por lo tanto es imposible desearlo por las solas fuerzas naturales con un deseo absoluto.

La visión de la esencia divina y lo sobrenatural, en general, no solamente está fuera del alcance de las facultades activas de la naturaleza racional, sino también fuera del campo de su apetito innato. El único vínculo ontológico que liga la naturaleza con lo sobrenatural es la potencia obediencial, concebida como mera capacidad receptiva, con ausencia de inclinación natural, y cuyo principio activo es la divina Omnipotencia: aun en el aspecto meramente receptivo, la naturaleza no puede tener, respecto de las perfecciones sobrenaturales, la misma proporción o actitud ontológica, que tiene respecto de las perfecciones de orden natural [...].

En conclusión: las dos verdades fundamentales, que constituyen el núcleo de la concepción de Cayetano, son dos: a) negación del apetito innato de la visión de Dios y de lo sobrenatural, en general; b) afirmación de la posibilidad del estado de naturaleza pura, deducida de la gratuidad de la visión beatífica y del orden sobrenatural, en general" ${ }^{67}$.

Para Alfaro, el planteamiento de Cayetano tiene el mérito de colocar en evidencia la debilidad fundamental que tiene la postura favorable a la existencia de un apetito innato respecto a la visión de la esencia divina, consistente en la falta de armonía o colisión entre tal deseo innato y el carácter gratuito que comporta dicha visión. Esta debilidad, a la vez, pone de relieve la dificultad más grave que tiene esta postura, no considerada por ninguno de sus representantes en los siglos previos, que radica precisamente en que, si la tendencia fundamental del alma humana tiene por objeto la visión de Dios; si por su misma naturaleza el ser intelectual apetece la visión de la esencia divina, tal visión, en cuanto objeto, debe ser el fin último del hombre, de lo contrario su existencia sería en vano, quedando definitivamente frustrada su tendencia natural a dicho objeto.

No obstante -por una parte- la centralidad motivacional que tiene el planteamiento de Cayetano en los albores de la reflexión antropoteo-

$\overline{67}$ J. Alfaro, Lo natural y lo sobrenatural. Estudio histórico..., 204-205. 
lógica de Alfaro y -por otra- la alta valoración que le otorga a la coherencia de dicho planteamiento, unida a la constatación de la inexistencia de argumentación sólida contraria, opta por la tesis tradicional-como quedará en evidencia en sus publicaciones posteriores- que sustenta la existencia del apetito innato, del cual se infiere no la necesidad ontológica de la visión de Dios, sino únicamente su posibilidad.

En el año 1957, en el artículo Trascendencia e inmanencia de lo sobrenatural, Alfaro vuelve a hacer referencia explícita a la tesis cayetana a propósito de la minimización que esta comportaría en relación a la inmanencia de la visión de Dios a favor de su gratuidad y trascendencia. Ahora bien, en el tratamiento de este problema, pienso que los mismos postulados que Alfaro realiza cuando desarrolla y explicita la relación Dioshombre en torno a las categorías creatura intelectual (en 1957 y después en 1973), persona (en 1960), y en las discusiones con otros autores al respecto, en el fondo dejan en evidencia que el reconocimiento que hace de la validez del planteamiento crítico de Cayetano en relación a la tesis tradicional mencionada, tienen repercusión en su reflexión, constituyéndose en fuente de la mencionada suerte de ambigüedad, observable en algunos de sus planteamientos, que, como se ha dicho, se irá atenuando en la medida que esa reflexión lo vaya llevando a asociar el surgimiento de la subjetividad en el proceso evolutivo -conciencia y libertad-con el factor divino señalado, lo cual se hace público en forma escrita en la primera edición de Revelación cristiana, fe y teología, correspondiente al año 1985.

Ciertamente -a modo de ejemplo- cuando Alfaro se pregunta en 1972 “¿Qué es el hombre?, ¿qué soy yo? ¿Soy simplemente el resultado fatal del dinamismo impersonal de la evolución cósmica, o mi existencia como ser personal y libre debe ser un fundamento personal trascendente, distinto del dinamismo evolutivo inmanente de la materia?"68, estaría entrando - pienso- en un punto de inflexión de su reflexión por cuanto se abriría a considerar el carácter personal del hombre como gracia y no como mero resultado impersonal de la evolución cósmica. En efecto, es posible que la valoración realizada al planteamiento de Teilhard de Chardin, quien considera a la conciencia y a la personalización como parte culminante de la tendencia inmanente de la evolución, en virtud de la cual nuestro autor justifica la gratuidad de la plenitud, esté entrando en revisión porque ella, en el fondo, constituye un soporte a la idea de felicidad natural presente

68 J. Alfaro, Esperanza cristiana y..., 225. 
al interior de la concepción que Marx y Bloch tienen del hombre y de la historia, idea que él manifiesta no compartir ${ }^{69}$.

Por otra parte, pero en esta misma línea de reflexión, cabe preguntarse ¿cómo una mera potencia obediencial, entendida como infraestructura antropológica previa para la recepción del llamado a la esperanza (cf. supra 3), puede al mismo tiempo ser el fundamento de la identidad en el hombre entre su acción de crear la historia y su acción de trascenderla? ${ }^{70}$. En este sentido, parece poco articulada la relación entre dicha infraestructura (entendida como receptáculo de pasiva obediencialidad) con el dinamismo propio del ser personal -espoleado por una fuerza oculta en él- que desborda toda planificación destinada al logro de una plenitud al interior del mundo, haciendo valer, de esta manera, su orientación hacia una plenitud trascendente y otorgando sentido a la responsabilidad de la libertad en el mundo y en la historia ante una realidad trascendente y personal. ¿Podría considerarse una identidad (ser la misma realidad) entre el Ser personal ante Quien la libertad es finalmente responsable y la fuerza oculta que la empuja a superar -en orden a la consecución de la plenitud- todo cálculo intramundano, orientándola así hacia la trascendencia? Desde esta perspectiva, el ser personal habría que considerarlo como algo más - por una parte- que una simple estructura antropológica obediencial que espera el llamado para activarse y que -por otra- un mero apetito innato, que, en caso de no ser satisfecho, tendría una existencia permanentemente frustrada (choque entre el deseo y la realidad que se impone a tal deseo) y acosada por el absurdo.

Por otro lado, ¿no es esta suerte de reducción del ser personal a una infraestructura previa que no es ni siquiera llamado previo a la esperanza, la que podría otorgar sustento al planteamiento de Bloch y a una interpretación marxista de la historia en orden a la construcción planificada de una plenitud intramundana? En efecto, sin la presencia de la realidad trascendente al interior del hombre, no se justifica la orientación dinámica de la libertad para que este sea más sí mismo a través de la

69 Cf. J. Alfaro, “Tecnopolis e...”, 543-545; J. Alfaro, Esperanza cristiana y ..., 25; 27 28; 184; J. Alfaro, "El hombre abierto a...”, 56-57; J. Alfaro, "Esperanza marxista y esperanza cristiana”, en Antropología y Teología; Consejo superior de investigaciones científicas; edición preparada por Horacio Santiago (Madrid 1978), 103; J. Alfaro, "Escatología, hermenéutica y lenguaje", en Salmaticensis 27 (1980), 237-238, J. AlfaRO, "Libertad y verdad", en Problemas de la Iglesia hoy (BAC, Madrid 1975), 60.

70 Cf. J. Alfaro, Esperanza cristiana y..., 28. 
superación permanente de toda meta alcanzada intramundanamente; se manifiesta como un contrasentido la apertura radical del hombre hacia la esperanza trascendente; $y$, desde esta perspectiva, es posible pensar en la realización de una plenitud al interior del mundo, regida por una razón lógica consensuada, que salvaguarda el bien común a través de un correcto funcionamiento social, en el que no podría echarse de menos una realidad existencial y aconceptualmente desconocida para el hombre: la trascendencia ${ }^{71}$.

La debilidad que - pienso- tiene el planteamiento de Bloch y de Marx no pasa necesariamente por la no consideración del movimiento de la libertad que tiende a desbordar toda planificación intramundana de la plenitud, sino porque sostendrían un optimismo antropológico poco realista, pues no estarían considerando en toda su radicalidad el profundo deterioro que existe en el hombre histórico entre los componentes cualitativos-subjetivos (conciencia y libertad, por ejemplo) y cuantitativosobjetivos (instinto y lógica racional, por ejemplo), que hacen imposible concluir en la posibilidad de una plenitud intramundana, estratégicamente planificada. En efecto, la experiencia cotidiana muestra el deseo de los sujetos de alcanzar la armonía relacional de dichos componentes en las relaciones con Dios, consigo mismo, con el mundo, con los otros, como anhelo de plenitud (felicidad) en el mundo; sin embargo, ello coexiste con el acoso de la nada, de la angustia, del absurdo, del totalitarismo emocional, del totalitarismo lógico, de la omnipotencia del instinto que, de diversos modos y en variadas ocasiones, somete a la razón.

2. En relación a la posibilidad de un nexo de necesidad interna entre la creaturalidad espiritual del hombre y su destino a la divinización en la visión de Dios

Esta dubitativa posición que tiene Alfaro respecto a la calidad del origen -divino o natural- de la subjetividad, se advierte en su manera de comprender la gratuidad de la visión de Dios - como ya se insinuaba a

71 En este sentido, ¿no se salvaguarda mejor la felicidad natural a partir de la concepción de una armónica relación razón-lógica e instinto -sin conciencia- como meta suprema de la evolución natural, la cual hubiese buscado su plena satisfacción natural, sin estar orientada (no le hubiera correspondido y por eso no tendría por qué asumir, como ha planteado Alfaro, actitudes suplicantes a la libertad soberana de Dios para ser llamada. Cf. J. Alfaro, "Trascendencia e inmanencia de lo sobrenatural”, 34-35) hacia una plenitud supratemporal? 
propósito del abordaje que realiza de las proposiciones de Cayetano-, manera que lo lleva a tomar distancia crítica del planteamiento que a este respecto, según él, sostendría $\mathrm{H}$. de Lubac.

Para Lubac, en efecto, existiría en el hombre un deseo natural absoluto respecto a la visión de Dios, que establecería un nexo de necesidad interna entre la creaturalidad espiritual del hombre y su destino a la divinización en la visión. En términos del propio Alfaro, el planteamiento de Lubac sería el siguiente en esta materia: "Afirmar que el hombre, en su misma dimensión esencial de espíritu-finito, es deseo natural absoluto de ver a Dios, equivale a decir que el hombre lleva en su mismo núcleo esencial creatural-espiritual la ordenación ontológica absoluta a la visión de Dios: en virtud de su misma condición esencial de espíritu creado el hombre está ya destinado necesaria y absolutamente a la visión. Entre su espiritualidad constitutiva y su destino a la visión hay un nexo real necesario: mejor dicho un nexo de identidad. El nexo entre la esencia creatural-espiritual del hombre y su destino a la divinización en la visión (el nexo entre lo natural y lo sobrenatural) es un nexo de necesidad interna, de plena y pura continuidad. La existencia de la creatura-intelectual sin el destino a la visión implicaría un total contrasentido interno, pues ese destino se identifica con el deseo natural absoluto constitutivo del espíritu-finito. Es, pues, evidente que, si el hombre es esencialmente deseo natural absoluto de ver a Dios, no puede existir ni ser creado sino con este destino a la visión, un destino que pertenece a su misma inteligibilidad de creatura-espiritual. El mismo Lubac, en perfecta lógica con su concepción del hombre como «deseo natural absoluto de ver a Dios», no puede menos de rechazar la posibilidad de la creación del hombre sin el destino a la visión: el hombre pudo no ser creado por Dios, pero no pudo ser creado sin el destino a la visión. No hay más gratuidad que la de la creación, porque la "creatura-espiritual» lleva en su misma dimensión «creatural-espiritual» el destino intrínseco absoluto a la autodonación de Dios. La concepción del hombre como «deseo natural absoluto de ver a Dios» y la afirmación de la gratuidad absoluta de la visión, como libre autodonación de Dios, parecen excluirse mutuamente.

Si el hombre, en su misma dimensión esencial es espíritu-creado, es deseo absoluto de la visión, está ya (en virtud de su misma esencia creatural-espiritual) llamado efectivamente a la visión. La gracia de la llamada a la visión, no solamente está vinculada necesariamente a su 
naturaleza-espiritual, sino que se identifica con ella. No hay más que una gracia, la de la creación. La llamada del hombre a la divinización está inscrita en la misma estructura creatural-espiritual del hombre de tal modo, que sin tal llamada el ser humano sería un contrasentido" ${ }^{72}$; se hallaría "en la situación de sufrimiento atroz"73.

A modo de complemento de lo señalado, y siguiendo al mismo Alfaro, se debe agregar que Lubac sostiene con fundamento sólido y original la gratuidad de la visión de Dios. En efecto, si bien el deseo de ver a Dios es esencial a la naturaleza espiritual del hombre, en cuanto expresa su ordenación ontológica fundamental, y en este sentido más que estar en el hombre es el hombre mismo ${ }^{74}$, "es un deseo (y aquí está lo más original de la explicación de Lubac), que anhela «la comunicación libre y gratuita de un ser personal». El espíritu no desea a Dios como el animal desea a su presa; lo desea como un don. No busca la posesión de un objeto [...] El deseo natural absoluto y necesario, constitutivo del hombre como espíritu, mira, pues, a la libre autodonación personal de Dios en la visión. Es un deseo «ineficaz por sí mismo», en cuanto no puede ser colmado por el hombre mismo sino únicamente por el don absoluto y absolutamente libre de Dios mismo; es un deseo que aspira a Dios como don personal de sí mismo, que espera que Dios se dé al hombre como el amor"75.

El planteamiento de Lubac que presenta Alfaro para delimitar su propia posición respecto al problema relativo a la trascendencia e inmanencia de la gracia me da base para plantear los siguientes alcances:

1. Lubac establecería una relación cercana y armónica entre el nivel de hecho (óntico) y el nivel de significado (ontológico) de la condición humana en el mundo.

En efecto, lo que de hecho objetivamente existe, es un hombre cuyo significado existencial emerge de su relación con el nivel profundo de

72 J. Alfaro, "El problema teológico...”, 285-286. Cf. H. DE LubaC, Surnaturel, Études historiques (París 1946); H. DE LubAC, Le Mystère du Surnaturel (París 1965), citados por Alfaro en "El problema teológico...", 259-288.

73 J. Alfaro, "El problema teológico...”, 335, nota 228.

74 Cf. H. DE LubaC, Surnaturel, Études historiques, 484; 488, citado por Alfaro en "El problema teológico...", 259, cita 50.

75 J. Alfaro, “El problema teológico...”, 259-260. Cf. 287. 
la realidad (con el nivel de sentido), de la cual surge la opción libre, no predecible, que lo vincula al amor.

Esa relación, que constituye la cuna de la historia y se despliega en ella, genera, por la condición temporal-creatural del hombre, la sensación de insaciable e irrenunciable búsqueda de significado existencial en el amor y la intuición de que la plenitud de este significado se halla supratemporalmente en la misma realidad que genera su apetencia. Queda de manifiesto de este modo en el pensamiento de Lubac, un nexo de necesidad ontológica respecto a la visión de Dios como plenitud absoluta, y que, sin embargo, estaría dejando intacta su gratuidad.

Efectivamente, la tesis del autor francés estaría suponiendo considerar la gracia de manera dinámica y unificante -no cercenadamente en relación a eventos-, y al hombre como un ser creado por Dios para ser feliz en el amor.

Tal felicidad, ciertamente, habría sido dada por Dios al momento mismo de la creación del hombre como deseo natural ontológico de plenitud de ser en el amor -en ese sentido absoluto-, y la seguiría manteniendo a través de una suerte de creación permanente de la nada.

Ahora bien, parece necesario en este punto, intentar realizar una comprensión de la gratuidad de la visión como plenitud en el amor, en el marco de la mencionada distinción entre el nivel óntico y ontológico de la realidad.

Por cierto, si la visión se reduce a un deseo natural de hecho, es decir a nivel óntico de la realidad, entonces la satisfacción de la necesidad que ese deseo comporta, estará orientada a la aprehensión o caza de un objeto a través de la razón lógica y/o del instinto hormonal, como una forma de insistir en el ser. Pero el mismo Alfaro indica que la originalidad del planteamiento de Lubac en este punto, radica precisamente en afirmar que el deseo natural absoluto de ver a Dios no es equivalente al deseo que tiene un animal respecto a su presa, que por sí mismo este deseo es ineficaz, que no busca poseerlo como objeto, que el espíritu humano, más bien, anhela a Dios como don, como Quien, desde Su Ser Personal, se autodona libre y gratuitamente como amor.

Esto significa que el amor de Dios, como tendencia de deseo para el hombre, implica -respecto a su consecución final- una actitud que lejos de ser acosante, insistente y exigente, ha de ser de espera suplicante, 
como expresión humilde de su condición de indigencia existencial en el ámbito del significado. Por eso es entendible una situación de sufrimiento por parte del hombre, como consecuencia de una hipotética toma de conciencia de que el deseo natural de ver a Dios -como deseo de felicidad perfecta- pudiera nunca alcanzar su efectivo cumplimiento.

Esto a su vez llevaría implícito que el hombre, de hecho, esté viviendo permanentemente en el significado y lo desee absolutamente como plenitud existencial. Ese, en efecto, sería el hombre histórico y real, el único que existiría desde el momento en que Dios habría hecho su irrupción en el curso evolutivo de la naturaleza creada, estableciendo un salto cualitativo en ella al hacer partícipe al mundo de la identidad existente en Él entre ser y ser consciente ${ }^{76}$.

Desde esta perspectiva, habría que entender la permanencia de la vida en el significado como permanencia en el ser, consecuencia del dinamismo activo de la gracia de Dios que crea constantemente de la nada al hombre -y al mundo a través de él-y lo sustenta hasta el final definitivo en $\mathrm{Su}$ visión.

En consecuencia, la existencia humana sería fundamentalmente existencia en la gracia. En esta, efectivamente, la existencia humana hallaría, por la activación de su dimensión afín -la conciencia-, las razones de sentido, no necesariamente lógicas, que darían base de convicción real -no ilusoria- a su opción fundamental de fe, esperanza y caridad, como respuesta al Dios de la gracia.

Esta respuesta, si bien es ineficaz por sí misma, estaría expresando el anhelo confiado -basado en el testimonio fidedigno de Dios que sustenta en el sentido- que Dios no dejará a su creatura en crianza en una eterna y absurda finalidad sin fin.

76 Cf. J. Alfaro, "Persona y Gracia”, en Gregorianum 41 (1960) 16. Para Alfaro existe una Identificación absoluta en Dios entre el Ser y el Ser-consciente. En efecto, como Dios es autoconciencia subsistente, plena autoluminosidad, sin división interna alguna entre sujeto y objeto -en el sentido que su posesión en conciencia no requiere tender hacia fuera de Sí mismo como ocurre en la situación del hombre (cf. J. Alfaro, "Persona y Gracia", 5)-, en Él se da una identidad entre Ser y Ser consciente, entre existencia y autoconciencia. Cf. J. Alfaro, "Persona y Gracia", 16; 19; J. Alfaro, "El problema teológico...", 243; 314, nota 181; 328; J. Alfaro, Esperanza cristiana y..., 16, nota 3; 187; J. Alfaro, "La dimensión trascendental en el conocimiento humano de Dios según S. Tomás”, en Gregorianum 55 (1974), 668; 673; J. Alfaro, “Esperanza marxista y esperanza cristiana”, 121, nota 76. 
Ahora bien, en el plano de la posibilidad hipotética, se puede inteligir que este sustento en el ser por el amor de Dios -creación constante de la nada-, como existencia en el significado, podría hundirse en la nada -en el sinsentido existencial- en caso de que Dios dejase de amar por un solo instante su creación. Esto mostraría que, si lo fundamental de la existencia humana real en la historia es pura dependencia, con cuánta mayor razón lo ha de ser respecto a la plenitud definitiva en la visión.

En este mismo plano de las ideas hipotéticas, comparto con Alfaro la posibilidad de que Dios pudo haber creado seres no llamados a Su visión y haberse realizado en el ámbito estrictamente natural. Pero en ese caso, dicho ser, que en la escala evolutiva pudo constituir el eslabón previo al salto cualitativo provocado por la irrupción de Dios (sin perjuicio de sus capacidades volitivas sujetas a un alto y en crecimiento nivel de intelecto lógico cuantitativo -coeficiente intelectual si se puede decir-, capaz de relacionarse con Dios como primer motor en el proceso de causas y efectos), carecería de la subjetividad conciencial participada, única dimensión que posibilita la apertura -como necesidad ontológicoexistencial- al encuentro dialogal intersubjetivo y filial con la subjetividad conciencial absoluta.

De haber sido así, habrá que convenir entonces que el ser personal, dado por la subjetividad conciencial, no pudo ser consecuencia del proceso evolutivo inmanente de la naturaleza creada (este, determinado por la predecible objetividad de sus procesos, no pudo haber evolucionado hacia el surgimiento de la subjetividad, cuya acción, en cuanto decisión consciente, es impredecible desde la lógica y el instinto), sino don de Dios. En este sentido, la subjetividad, fundamento del ser personal, es gracia; presencia en el mundo -inmanencia- de la trascendencia.

En efecto, Dios ha creado al hombre como sujeto relacionable en el amor, y para ello, le ha participado algo de Sí, en virtud de lo cual se le ha dado a conocer en el plano de la intuición, es decir, aconceptualmente. Esta participación de Sí -considero- se identifica con la conciencia, la cual se constituye en código de sintonía ontológica, capaz de hurgar en el misterio significante de la realidad, más al fondo de su nivel periférico funcional: ahí, donde pueda entrar en sintonía con la dimensión de sentido que funda su opción de verdadera libertad hecha efectiva en su amorosa donación esperante. Por eso, la relación en el amor -en la gratuidad- tiene su eje impulsor inicial en el conocimiento intuitivo- 
cualitativo (aconceptual), y hacia este han de converger las otras dimensiones de lo humano: racionalidad lógica, instinto, etc.

2. Así como Lubac -considero- establece una relación armónica entre el nivel de hecho y el nivel de significado de la condición humana, en Alfaro esta relación, al interior de la temática que se está tratando, se ve algo difusa, lo cual, es probable, tenga su origen en el hecho de que, en los años setenta, están convergiendo en él tres planteamientos que entran en tensión.

Efectivamente, tal como se ha indicado, Alfaro - por una parte- sostiene que la conciencia es presupuesto necesario para la gracia y no su efecto, pero también sostiene - por otra parte- la existencia de una frontera indeterminada en la relación que se da entre ambas, causante de la imposibilidad de distinguir con seguridad, al interior de la experiencia vital concreta, aquello que es propio de la estructura finita espiritual del hombre.

Ahora bien, un tercer factor que podría estar tensionando el pensamiento de Alfaro en este período radicaría en la relación que él estaría estableciendo entre su postura favorable a la hipótesis de la posibilidad de una felicidad natural, en el supuesto que Dios no hubiese llamado al hombre a Su visión ${ }^{77}$, y su postura crítica al planteamiento de Bloch y de Marx relativo a la posibilidad - para la humanidad- de una plenitud futura inmanente dentro del mundo, posturas que en el fondo, paradójicamente, estarían coincidiendo, generando un conflicto intelectual, que -entiendo- lo llevará, posteriormente, a plantear la existencia de un plus divino en el proceso evolutivo de la naturaleza material.

Dicho plus, tal cual se ha visto, es presentado por Alfaro como fundamento de la conciencia y de la libertad -de la condición de persona humana-, en virtud del cual el hombre recibe la esperanza ilimitada como apertura hacia un más allá de los límites inmanentes de la muerte y de la historia, que impide su reducción a un mero instrumento impersonal y anónimo en el dinamismo del devenir de dicha historia.

Como se puede apreciar, este último planteamiento se ubica en el lado opuesto al inicial, que reducía a la conciencia a un mero presupuesto necesario para la gracia.

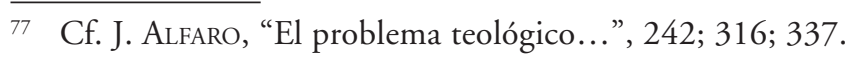


En virtud de esto, dicho presupuesto tendría que radicar ahora en la dimensión cuantitativa y predecible de lo humano (racionalidad lógica e instinto, correspondientes al nivel de hecho de la realidad), en su indeterminada orientación hacia la ilimitación formal del ser ${ }^{78}$.

Finalmente, supuesta la validez de lo señalado, parece coherente afirmar que la felicidad y el sufrimiento están asociados a la conciencia de sentido y de sinsentido existencial, respectivamente. Ello implica, en consecuencia, reconocer la existencia de la subjetividad como correspondiente al nivel ontológico-significativo de la condición humana:

Este sería, de hecho, el hombre histórico y real, radicalmente distinto al supuesto ser que pudo no ser llamado a la visión de Dios, el cual, dentro de su perfección natural -carente de conciencia y libertad-, se hubiera movido dentro del plano predecible y lógico, en un constante desarrollo tendiente al progreso indefinido, no necesariamente asociado a una plenitud supratemporal (plenitud de coincidencia entre ser y ser consciente), sino más bien asociado a una suerte de felicidad natural-óntica (satisfacción orgánica-intelectual), como consecuencia de la relación armónica entre la racionalidad lógica y el instinto, y donde la frustración estaría más emparentada al dolor y al error y no necesariamente a la angustia.

78 Cf. J. Alfaro, Hacia una teología..., 40, nota 2; 67; J. Alfaro, "El problema teológico...", 320. 